\title{
Fatal high-grade skull osteosarcoma 30 years following radiotherapy for Cushing's disease
}

\author{
Mawson Wang 1,2, Benjamin Jonker3 ${ }^{3}$ Louise Killen4, Yvonne Bogum5 \\ Ann McCormack $6,7,8$ and Ramy H Bishay ${ }^{1,2}$
}

1Department of Endocrinology and Diabetes, Blacktown Hospital, Sydney, Australia, 2Blacktown Clinical School, School of Medicine, Western Sydney University, Sydney, Australia, ${ }^{3}$ Department of Neurosurgery, St. Vincent's Hospital, Sydney, Australia, 4Department of Pathology, St. Vincent's Hospital, Sydney, Australia, 5NSW Health Pathology East, Prince of Wales Hospital, Sydney, Australia, ${ }^{\circ}$ Department of Endocrinology, St. Vincent's Hospital, Sydney, Australia, ${ }^{7}$ Garvan Institute of Medical Research, Sydney, Australia, and ${ }^{8 S t}$. Vincent's Clinical School, Faculty of Medicine, UNSW Sydney, Sydney, Australia

\author{
Correspondence \\ should be addressed \\ to M Wang \\ Email \\ mawson.wang@health.nsw. \\ gov.au
}

\section{Summary}

Cushing's disease is a rare disorder characterised by excessive cortisol production as a consequence of a corticotroph pituitary tumour. While the primary treatment is surgical resection, post-operative radiation therapy may be used in cases of ongoing inadequate hormonal control or residual or progressive structural disease. Despite improved outcomes, radiotherapy for pituitary tumours is associated with hypopituitarism, visual deficits and, rarely, secondary malignancies. We describe an unusual case of a 67-year-old female with presumed Cushing's disease diagnosed at the age of 37, treated with transsphenoidal resection of a pituitary tumour with post-operative external beam radiotherapy (EBRT), ketoconazole for steroidogenesis inhibition, and finally bilateral adrenalectomy for refractory disease. She presented 30 years after her treatment with a witnessed generalised tonic-clonic seizure. Radiological investigations confirmed an extracranial mass infiltrating through the temporal bone and into brain parenchyma. Due to recurrent generalised seizures, the patient was intubated and commenced on dexamethasone and anti-epileptic therapy. Resection of the tumour revealed a highgrade osteoblastic osteosarcoma. Unfortunately, the patient deteriorated in intensive care and suffered a fatal cardiac arrest following a likely aspiration event. We describe the risk factors, prevalence and treatment of radiation-induced osteosarcoma, an exceedingly rare and late complication of pituitary irradiation. To our knowledge, this is the longest reported latency period between pituitary irradiation and the development of an osteosarcoma of the skull.

\section{Learning points:}

- Cushing's disease is treated with transsphenoidal resection as first-line therapy, with radiotherapy used in cases of incomplete resection, disease recurrence or persistent hypercortisolism.

- The most common long-term adverse outcome of pituitary tumour irradiation is hypopituitarism occurring in $30-60 \%$ of patients at 10 years, and less commonly, vision loss and oculomotor nerve palsies, radiation-induced brain tumours and sarcomas.

- Currently proposed characteristics of radiation-induced osteosarcomas include: the finding of a different histological type to the primary tumour, has developed within or adjacent to the path of the radiation beam, and a latency period of at least 3 years.

- Treatment of osteosarcoma of the skull include complete surgical excision, followed by systemic chemotherapy and/or radiotherapy.

- Overall prognosis in radiation-induced sarcoma of bone is poor.

- Newer techniques such as stereotactic radiosurgery may reduce the incidence of radiation-induced malignancies. 


\section{Background}

Pituitary tumours are common, with an estimated prevalence of $16.7 \%$ based on autopsy and radiologic studies (1). The relative prevalence of adrenocorticotropin (ACTH)-secreting (corticotroph) tumours, or Cushing's disease, is only 2-\% of pituitary adenomas (2). Untreated Cushing's disease conveys significant morbidity and mortality, with a 5-year survival rate of 50\% attributable to cardiovascular and metabolic complications (3). Surgery is standard of care first-line treatment for corticotroph tumours (4). Post-operative radiotherapy may be indicated for incomplete resection, local recurrence or persistent hormonal secretion, and this may occur in up to $20-30 \%$ of patients with Cushing's disease $(4,5)$. The combination of surgery and radiotherapy leads to normalisation of hormonal control in 54-75\% and local tumour control in $83-100 \%$ of cases (6). Medical therapy may be used as second-line therapy, or when awaiting effects of radiotherapy, and includes drugs targeted against the somatostatin receptor to inhibit ACTH secretion (pasireotide), dopamine receptor to inhibit ACTH secretion (cabergoline), glucocorticoid receptor (mifepristone), or adrenal glucocorticoid production (ketoconazole, metyrapone, osilodrostat) (5, $6,7)$. Bilateral adrenalectomy is indicated in refractory or life-threatening Cushing's disease when requiring rapid correction of hypercortisolism or when other therapies have failed, as in our case (5).

Although undoubtedly an effective adjunct treatment in the treatment of pituitary tumours, radiotherapy may result in potential complications including hypopituitarism, optic neuropathy, stroke and secondary malignancies (6).

\section{Case presentation}

We report a case of a 37-year-old female diagnosed with presumed Cushing's disease in 1986 on the basis of clinical and biochemical hypercortisolism and suppressed cortisol levels on a dexamethasone infusion test. Pituitary imaging did not visualise a pituitary tumour, CT of abdomen and pelvis did not reveal an obvious ectopic tumour, and inferior petrosal sinus sampling was not performed. Nevertheless, the clinical picture was thought to be consistent with Cushing's disease, and the endocrinologist at the time made a decision for primary transsphenoidal surgery, which failed to demonstrate a corticotroph tumour. She then received adjunctive $5000 \mathrm{rad}$ of EBRT due to persistent hypercortisolism several months post-operatively. She required subsequent medical therapy with ketoconazole to inhibit adrenal steroidogenesis for several years with variable control of hypercortisolism. Her treating endocrinologist advised for a bilateral adrenalectomy with prompt resolution of hypercortisolism. She was maintained on replacement glucocorticoid and mineralocorticoid therapy (prednisolone $6 \mathrm{mg}$ daily and fludrocortisone $100 \mu \mathrm{g}$ daily), as well as thyroxine $50 \mu \mathrm{g}$ daily for central hypothyroidism. She was not on growth hormone replacement but did previously require estradiol replacement for several years.

Her other comorbidities included ischaemic heart disease with coronary artery stenting, hypertension, peptic ulcer disease, glucocorticoid-induced osteoporosis with vertebral fractures not on treatment, chronic pain, depression and a 40 pack-year smoking history. At age 67, she was brought to her regional emergency department following a witnessed generalised tonic-clonic seizure with prolonged post-ictal state. No other history was able to be elicited apart from progressive lethargy and possible alcohol excess prior to presentation. There was no past seizure disorder.

\section{Investigations}

Laboratory investigations on admission identified a mixed respiratory and metabolic alkalosis ( $\mathrm{pH}$ : 7.63, $\left.\mathrm{HCO}_{3}{ }^{-}: 32 \mathrm{mmol} / \mathrm{L}, \mathrm{pCO}_{2}: 26 \mathrm{mmHg}\right)$. There was mild hyponatraemia (132 mmol/L (135-145)), hypokalaemia (3.2 mmol/L (3.2-5.0)), and renal impairment (creatinine: $79 \mu \mathrm{mol} / \mathrm{L}(60-110)$, estimated glomerular filtration rate: $\left.67 \mathrm{~mL} / \mathrm{min} / 1.72 \mathrm{~m}^{2}(\geq 90)\right)$. Pituitary hormonal panel performed on the morning of day 3 of her admission was consistent with hypopituitarism. Her follicular stimulating hormone level and luteinising hormone levels were 1.3 IU/L (25.0-140.0) and <0.5 IU/L (7.7-60.0), respectively, low in the setting of menopause. Thyroid function was consistent with central hypothyroidism with a thyrotrophin releasing hormone level of $0.04 \mathrm{mIU} / \mathrm{L}$ (0.40-4.20) and a normal free thyroxine of $17.5 \mathrm{pmol} / \mathrm{L}$ (11.0-22.0) on thyroxine replacement. Prolactin level was normal at $74 \mathrm{mIU} / \mathrm{L}$ (50-500). A serum cortisol level was $32 \mathrm{nmol} / \mathrm{L}$ (150-520) while receiving dexamethasone for several days. Unfortunately, no adrenocorticotrophic hormone level was obtained prior to the administration of dexamethasone. Growth hormone and insulin-like growth factor 1 were not measured. Her blood haematology, liver function tests, coagulation profile and C-reactive protein were within normal range. 
MRI (Fig. 1) on presentation demonstrated an extracranial soft-tissue mass infiltrating the right temporal bone and involving both temporal and parietal lobes.

\section{Treatment}

Based on the clinical presentation and CT findings, the patient was immediately commenced on oral dexamethasone $8 \mathrm{mg}$ TDS to reduce cerebral oedema and levetiracetam $500 \mathrm{mg}$ BD for seizure prophylaxis. She experienced further generalised tonic-clonic seizures on the medical ward, requiring IV midazolam and phenytoin, followed by emergency sedation and intubation. Repeat CT brain demonstrated haemorrhage into the intracranial component of the infiltrating mass, and the decision was made for urgent transfer to a tertiary intensive care unit with neurosurgical support on day 3. Medications on intensive care admission were intravenous dexamethasone $4 \mathrm{mg}$ TDS, levetiracetam: $500 \mathrm{mg} \mathrm{BD}$, thyroxine: $50 \mu \mathrm{g}$ OD, fludrocortisone: $100 \mu \mathrm{g}$ OD and thiamine: $100 \mathrm{mg}$ OD (given the possibility of alcohol excess based on history). She required noradrenaline for inotropic support and exhibited a fluctuating level of consciousness and delirium. She was dependent on NG feeds and i.v. dextrose to maintain normoglycaemia. MRI brain (Fig. 1) demonstrated a large mass effacing the temporal bone with partial extra- and intracranial extension, extensive perilesional oedema and compression of the temporal horn of the right lateral ventricle. The radiological findings were most in keeping with osteosarcoma, although differential diagnoses included chondrosarcoma and haemangiopericytoma arising from the osseous vault. CT abdomen and pelvis did not yield evidence of metastatic or another source of primary malignancy (not shown).

On day 5 of admission, she underwent stereotactic resection of right temporal tumour and cranioplasty. A post-operative CT brain (Fig. 2) confirmed removal of the intracranial mass, although no attempt was made to completely excise all involved bone.

\section{Outcome and follow-up}

Extubation occurred on day 9 of admission, with transient improvement in neurological status and delirium, before the patient suffered a cardiac arrest from a likely aspiration event on day 12. After several attempts at cardiopulmonary resuscitation, a decision was made to cease further resuscitation and she was pronounced deceased.

On histopathological examination (Fig. 3), the tumour was a conventional osteoblastic osteosarcoma
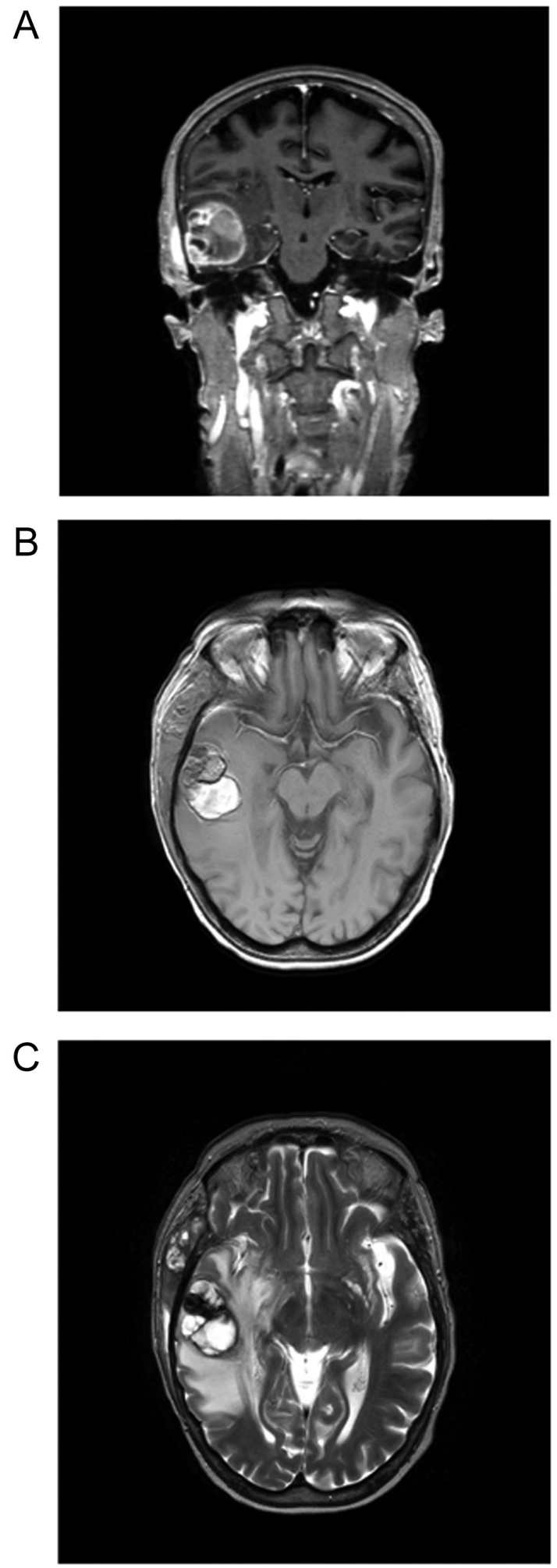

Figure 1

Brain MRI with gadolinium enhancement. (A) Coronal T1, (B) Axial T1, and (C) Axial T2 sections demonstrating a large mass effacing the right temporal bone, with evidence of fluid levels and haemorrhage. There is extensive perilesional oedema and compression of the temporal horn of the right lateral ventricle. 
A

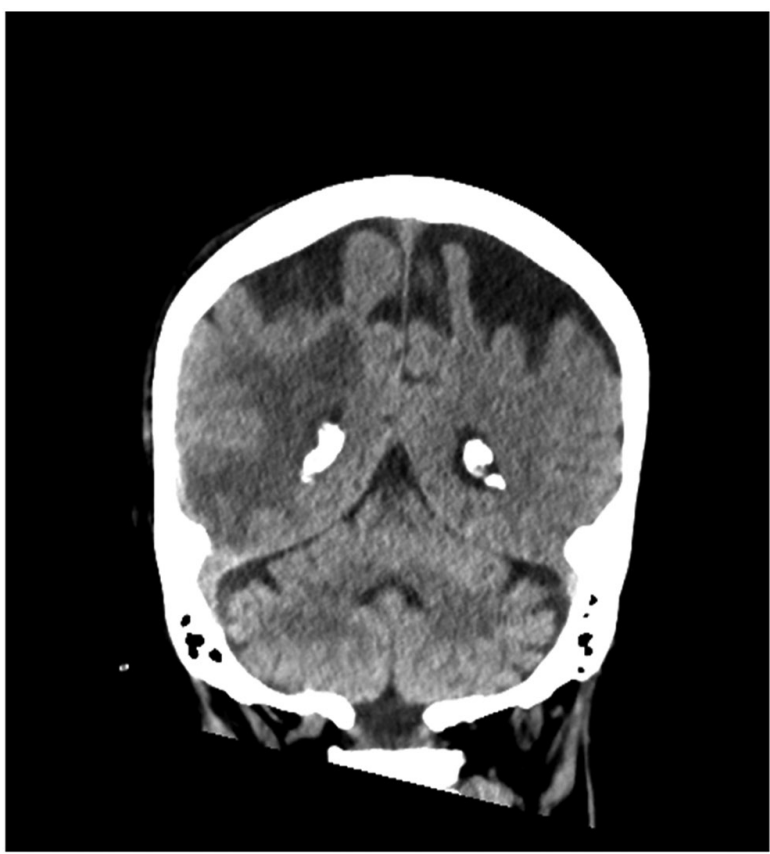

B

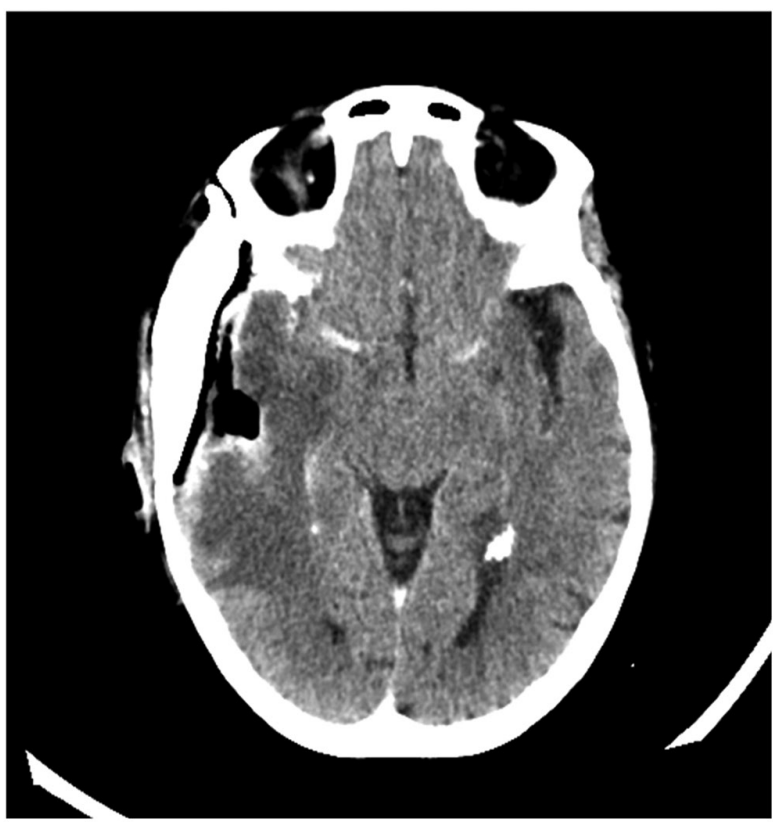

Figure 2

(A) Post-operative coronal and (B) axial CT sections indicating no post-operative haemorrhage, but persisting mass effect and cerebral oedema with effacement of the right cerebral sulci.

with a high-grade component. The tumour arose from the cortical bone of the skull and invaded into the adjacent skeletal muscle and brain parenchyma. It contained large areas of malignant osteoid and small areas of atypical chondroid material. It was moderately to markedly hypercellular and was composed of cells with an epithelioid to spindled appearance. The nuclei were markedly pleomorphic with hyperchromatic, irregularly
A

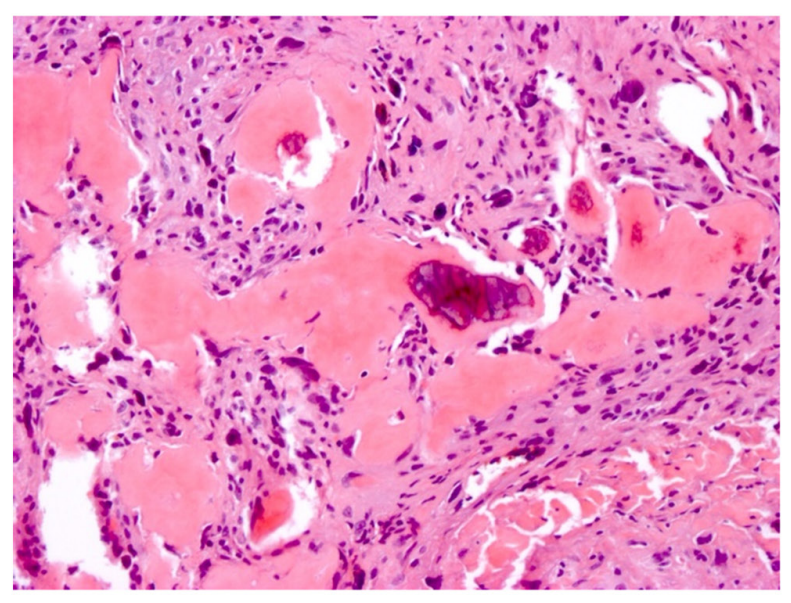

B

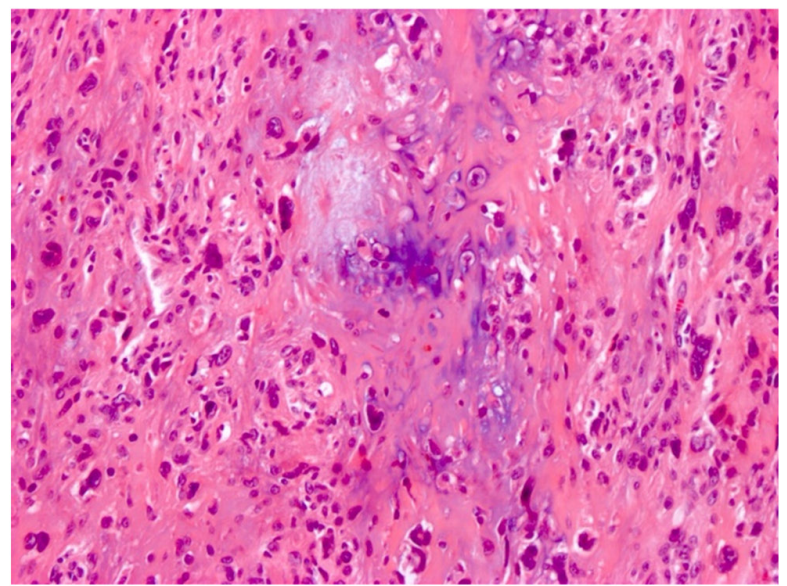

C

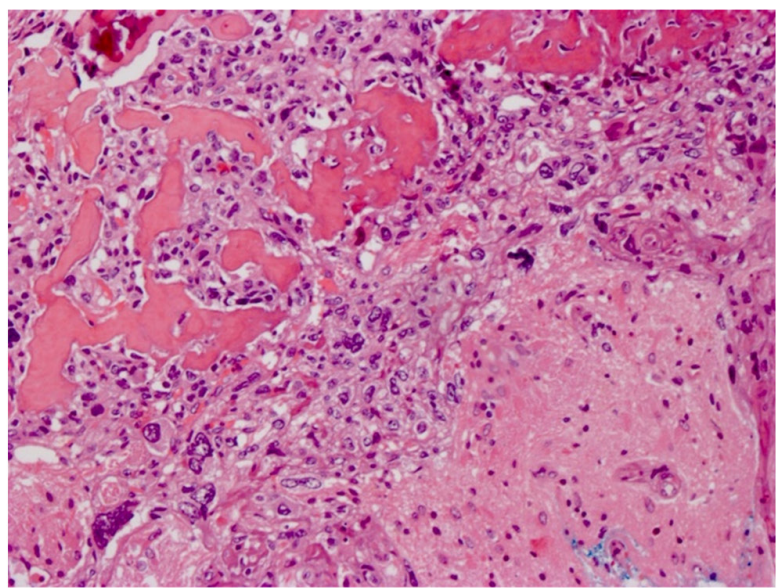

Figure 3

(A) The tumour contained lace-like areas of partly-calcified osteoid and intervening malignant osteoblasts. (B) The tumour cell nuclei were markedly enlarged, hyperchromatic and pleomorphic, and many were multinucleated. (C) The tumour is seen invading adjacent brain parenchyma (lower right of image).

shaped nuclei and coarse chromatin. Many multinucleated forms were present. Numerous mitoses, including atypical form were seen. Lymphovascular invasion was 
seen. Immunohistochemistry results were consistent with an osteosarcoma, with the lesion being negative for melanocytic markers (Mart-1, HMB45 and SOX10), myogenic markers (desmin and myogenin), a vascular marker (ERG), an epithelial marker (pancytokeratin), a glial marker (GFAP) and a marker for solitary fibrous tumour (STAT6).

\section{Discussion}

Radiotherapy is an effective treatment for corticotroph tumours with incomplete resection or hormonal control after primary surgery, resulting in normalisation of hypercortisolism in $54-75 \%$ of cases (8). Compared to conventional EBRT, newer techniques of stereotactic radiosurgery (SRS) or fractionated stereotactic radiotherapy (FSRT) have refinements in patient immobilisation, imaging and dose distribution, thus delivering more localised radiation (9). Nevertheless, complications of modern radiotherapy include hypopituitarism in up to 30-60\% of patients by 10 years post-treatment and, less commonly, radiation-induced optic neuropathy, stroke and secondary tumours in $0-3 \%$ of cases (9). Ionising radiation causes double-strand DNA damage and genomic instability, thereby increasing the risk of secondary malignancy (10). Mutations of the p53 tumour suppressor gene, upregulated in response to DNA damage, are also more common in radiationinduced sarcomas than sporadic soft-tissue sarcomas (10). The risk of radiotherapy-induced secondary brain tumours in individuals with pituitary tumours has been reported variably in the literature. An earlier cohort of 336 patients who received radiotherapy following pituitary surgery between 1962 and 1986 demonstrated a cumulative risk of secondary brain tumour of $1.9 \%$ at 20 years (95\% CI: $0.7-5.0 \%$ ), with a relative risk of 9.38 (95\% CI: 3.05-21.89) compared to the normal population (11). This study was extended for an additional 10 years with further recruitment and confirmed a cumulative risk of $2.4 \%$ at 20 years (95\% CI: 1.2-5.0\%) (11). Meningiomas and high-grade astrocytomas were the most common secondary brain tumours, and only one patient developed a sarcoma (11). However, a different cohort of 462 patients who received radiotherapy between 1956 and 2008 did not report an increased incidence of either intracranial or extracranial tumours, or overall mortality (4). Pituitary tumours themselves are not thought to be associated with an increased risk of other malignancy, except in the case of growth-hormone secreting tumours and those with a hereditary cancer syndrome such as multiple endocrine neoplasia type 111 (12). Although not proven, immunosuppression due to hypercortisolism in Cushing's disease has been proposed as a contributor to secondary tumour development (12).

Criteria for the diagnosis of a radiation-induced sarcoma has been proposed and include the following: (1) presence of non-malignancy or malignancy of a different histological type before irradiation, (2) development of sarcoma within or adjacent to the path of the radiation beam, (3) latency period of at least 3 years between irradiation and diagnosis of secondary tumour, and (4) histological diagnosis of secondary sarcoma (13). Our patient fulfilled all the criteria for a radiationinduced sarcoma, with histopathology confirming an osteosarcoma. The most common histological subtypes of radiation-induced sarcoma of the bone include osteosarcoma, followed by spindle-cell sarcoma, malignant fibrous histiocytoma and leiomyosarcoma (14). The risk of radiation-induced osteosarcoma following radiotherapy is exceedingly rare, occurring in $0.01-0.03 \%$ of all irradiated patients, and observed more commonly in malignant indications for radiotherapy (15). They account for $5.5 \%$ of all osteosarcomas and behave more aggressively than primary osteosarcomas (15). Although the term implies the causative role of radiation in tumourigenesis, the contributory effects of genetic predisposition or concurrent chemotherapy in oncology indications should not be undermined (10). The risk of radiation-induced sarcomas increases with dose and field size, with the minimum and median dose of cumulative radiation thought to cause a secondary sarcoma estimated to be 20 and $50 \mathrm{~Gy}$, respectively (14). Our patient received $5000 \mathrm{rad}$, equivalent to $50 \mathrm{~Gy}$, through EBRT and thus the field size was significantly larger than one would expect with a modern stereotactic treatment. The risk of secondary malignancy with SRS is thought to be much lower than conventional EBRT, with an estimated cumulative incidence of $0.00045 \%$ over 10 years (CI $0.00-0.0034 \%$ ) (16). However, it should be noted that long-term follow-up data for patients receiving SRS are shorter than that of ERBT and thus definitive conclusions cannot be made at this stage.

Oncological literature from non-pituitary cases sheds some light on the association of radiation-therapy exposure and secondary malignancies. A review of 42 radiation-induced sarcomas of the bone with primary malignant indications showed a mean latent interval of 17 years (4-50) with a median dose of radiotherapy of 50 Gy (20-66) (14). 
Table 1 Case reports of radiation-induced osteosarcoma following pituitary tumour irradiation. Our case is included for comparison.

\begin{tabular}{|c|c|c|c|}
\hline Author, year & Age & Radiation dose & $\begin{array}{c}\text { Latency } \\
\text { (years) }\end{array}$ \\
\hline Meredith et al. (19) & 57 & $2052 \mathrm{rad}$ & 6 \\
\hline Sparagana et al. (20) & 50 & $7750 \mathrm{rad}$ & 21 \\
\hline Amine \& Sugar (22) & 16 & 51 Gy & 10 \\
\hline Sugita et al. (21) & 65 & $5000 \mathrm{rad}$ & 7 \\
\hline Salvati et al. 23) & 45 & 44 Gy & 12 \\
\hline Gnanalingham et al. (24) & 67 & $52 \mathrm{~Gy}$ & 14 \\
\hline Hansen \& Moffat (25) & 29 & $5000 \mathrm{rad}$ & 22 \\
\hline Bembo et al. (26) & 45 & 46 Gy & 5 \\
\hline Yamada et al. (12) & 75 & $50 \mathrm{~Gy}$ & 20 \\
\hline This case report & 67 & $5000 \mathrm{rad}$ & 30 \\
\hline
\end{tabular}

\begin{tabular}{l} 
Site of osteosarcoma \\
\hline Temporal bone \\
Frontal bone \\
Sella \\
Frontotemporal bone \\
Sphenoid \\
Sella \\
Sphenoid, frontal clivus \\
Sella \\
Sphenoid sinus \\
Temporal bone
\end{tabular}

\begin{tabular}{ll}
\hline & \\
Treatment & Prognosis \\
\hline Surgery & 5 months \\
Surgery & 5 weeks \\
Radiation & - \\
Surgery, chemotherapy & 16 months \\
Radiation & - \\
Surgery & Very short \\
Chemotherapy & 7 weeks \\
Surgery & $>24$ months \\
Cyberknife surgery, & \\
$\quad$ Chemotherapy & Days \\
Surgery & \\
\hline
\end{tabular}

Our case is included for comparison.

The prevalence of radiation-induced osteosarcoma and other sarcomas of the skull in patients with prior radiotherapy for pituitary tumours has not been established and is largely described through case reports. Secondary tumours may arise in bone at the borders of the radiation field, where the radiation dose was sufficient to cause malignant transformation but insufficient to cause cell death (17). Table 1 describes the characteristics of nine other cases of radiation-induced osteosarcoma following pituitary tumour irradiation. The mean age at diagnosis of secondary tumour was 50 years (16-75) with a mean latency period of 13 years (5-22). At 30 years, this is the longest reported duration between radiotherapy for a pituitary tumour and development of a radiationinduced osteosarcoma in the literature. The sites of osteosarcoma in reported cases were divided between the skull and base of skull. Complete surgical excision, while the treatment of choice, was often ineffective due to tumour adherence and invasion of surrounding structures $(12,14)$. Chemotherapy was offered as either curative or palliative intent and involved standard bone sarcoma regimens such as doxorubicin, cisplatin and methotrexate (10). Further radiotherapy is usually not advisable due to limits of normal tissue tolerance from prior irradiation (10). One case report demonstrated the efficacy of Cyberknife treatment to a base of skull radiation-induced osteosarcoma with complete resolution of neurological symptoms for over 24 months (18). Most cases had short survival periods. Literature also affirms an overall poor prognosis, with a 5-year disease-free survival time of $17 \%$ and median survival of 8.8 months in palliative cohorts $(14,15)$.

Our case highlights a rare but devastating longterm complication of pituitary tumour irradiation.
Radiation-induced osteosarcomas can arise in either the base of skull or the calvarium, as in this case. These tumours by definition occur years after primary irradiation with a dose-dependent increase in risk. Management consists of surgical resection followed by systemic chemotherapy, although patients often present with advanced disease unamenable to treatment, with poor outcome. Long-term follow-up studies on patients receiving SRS or FSRT are warranted to examine the risk of development of such tumours.

Declaration of interest

The authors declare that there is no conflict of interest that could be perceived as prejudicing the impartiality of the research reported.

\section{Funding}

This research did not receive any specific grant from any funding agency in the public, commercial or not-for-profit sector.

\section{Patient consent}

Written informed consent was unable to be obtained from the patient as she was deceased at the time of report writing. An attempt to contact the next of kin was unsuccessful. All care was taken to ensure confidentiality in this case.

\section{Author contribution statement}

M W wrote the manuscript. L K and $Y$ B provided the histopathology slides. B J, A M and R B were involved in the management of the case and contributed to writing this manuscript.

\section{References}

1 Ezzat S, Asa SL, Couldwell WT, Barr CE, Dodge WE, Vance ML \& McCutcheon IE. The prevalence of pituitary adenomas: a systematic 
review. Cancer 2004101 613-619. (https://doi.org/10.1002/ cncr.20412)

2 Melmed S. Pituitary-tumor endocrinopathies. New England Journal of Medicine 2020382 937-950. (https://doi.org/10.1056/NEJMra1810772)

3 Plotz CM, Knowlton AI \& Ragan C. The natural history of Cushing's syndrome. American Journal of Medicine 195213 597-614. (https:// doi.org/10.1016/0002-9343(52)90027-2)

4 Sattler MG, van Beek AP, Wolffenbuttel BH, van den Berg G, Sluiter WJ, Langendijk JA \& van den Bergh AC. The incidence of second tumours and mortality in pituitary adenoma patients treated with postoperative radiotherapy versus surgery alone. Radiotherapy and Oncology 2012104 125-130. (https://doi.org/10.1016/j. radonc.2012.04.024)

5 Katznelson L. Bilateral adrenalectomy for Cushing's disease. Pituitary 201518 269-273. (https://doi.org/10.1007/s11102-014-0633-2)

6 Ferriere A, Cortet C, Chanson P, Delemer B, Caron P, Chabre O, Reznik Y, Bertherat J, Rohmer V, Briet C, et al. Cabergoline for Cushing's disease: a large retrospective multicenter study. European Journal of Endocrinology 2017176 305-314. (https://doi.org/10.1530/ EJE-16-0662)

7 Fleseriu M, Pivonello R, Young J, Hamrahian AH, Molitch ME, Shimizu C, Tanaka T, Shimatsu A, White T, Hilliard A et al. Osilodrostat, a potent oral $11 \beta$-hydroxylase inhibitor: 22 -week, prospective, Phase II study in Cushing's disease. Pituitary 201619 138-148. (https://doi.org/10.1007/s11102-015-0692-z)

8 Tritos NA \& Biller BM. Update on radiation therapy in patients with Cushing's disease. Pituitary 201518 263-268. (https://doi. org/10.1007/s11102-014-0615-4)

9 Minniti G, Clarke E, Scaringi C \& Enrici RM. Stereotactic radiotherapy and radiosurgery for non-functioning and secreting pituitary adenomas. Reports of Practical Oncology and Radiotherapy 201621 370-378. (https://doi.org/10.1016/j.rpor.2014.09.004)

10 Patel SR. Radiation-induced sarcoma. Current Treatment Options in Oncology 20001 258-261. (https://doi.org/10.1007/s11864-000-0037-6)

11 Minniti G, Traish D, Ashley S, Gonsalves A \& Brada M. Risk of second brain tumor after conservative surgery and radiotherapy for pituitary adenoma: update after an additional 10 years. Journal of Clinical Endocrinology and Metabolism 200590 800-804. (https://doi. org/10.1210/jc.2004-1152)

12 Yamanaka R, Abe E, Sato T, Hayano A \& Takashima Y. Secondary intracranial tumors following radiotherapy for pituitary adenomas: a systematic review. Cancers 20179 103. (https://doi.org/10.3390/ cancers9080103)

13 Arlen M, Higinbotham NL, Huvos AG, Marcove RC, Miller T \& Shah IC. Radiation-induced sarcoma of bone. Cancer 197128 1087-1099. (https://doi.org/10.1002/1097-0142(1971)28:5<1087::aidcncr2820280502>3.0.co;2-f)

14 Kalra S, Grimer RJ, Spooner D, Carter SR, Tillman RM \& Abudu A. Radiation-induced sarcomas of bone: factors that affect outcome. Journal of Bone and Joint Surgery: British Volume 200789 808-813. (https://doi.org/10.1302/0301-620X.89B6.18729)
15 Echchikhi Y, Loughlimi H, Touil A, Kebdani T \& Benjaafar N. Radiation-induced osteosarcoma of the skull base after radiation therapy in a patient with nasopharyngeal carcinoma: a case report and review of the literature. Journal of Medical Case Reports $2016 \mathbf{1 0}$ 334. (https://doi.org/10.1186/s13256-016-1112-3)

16 Wolf A, Naylor K, Tam M, Habibi A, Novotny J, Liščák R, MartinezMoreno N, Martinez-Alvarez R, Sisterson N, Golfinos JG, et al. Risk of radiation-associated intracranial malignancy after stereotactic radiosurgery: a retrospective, multicentre, cohort study. Lancet: Oncology 201920 159-164. (https://doi.org/10.1016/S14702045(18)30659-4)

17 Lee YY, Van Tassel P, Nauert C, Raymond AK \& Edeiken J. Craniofacial osteosarcomas: plain film, CT, and MR findings in 46 cases. American Journal of Roentgenology 1988150 1397-1402. (https://doi.org/10.2214/ajr.150.6.1397)

18 Yamada SM, Ishii Y, Yamada S, Kuribayashi S, Kumita S \& Matsuno A. Advanced therapeutic strategy for radiation-induced osteosarcoma in the skull base: a case report and review. Radiation Oncology 20127 136. (https://doi.org/10.1186/1748-717X-7-136)

19 Meredith JM, Mandeville FB \& Kay S. Osteogenic sarcoma of the skull following roentgen-ray therapy for benign pituitary tumor. Journal of Neurosurgery 196017 792-799. (https://doi.org/10.3171/ jns.1960.17.4.0792)

20 Sparagana M, Eells RW, Stefani S \& Jablokow V. Osteogenic sarcoma of the skull: a rare sequela of pituitary irradition. Cancer 197229 1376-1379. (https://doi.org/10.1002/10970142(197205)29:5<1376::aid-cncr2820290539>3.0.co;2-1)

21 Sugita Y, Shigemori M, Miyagi J, Ochiai S, Lee S, Watanabe T, Abe H \& Morimatsu M. Radiation-induced osteosarcoma of the calvaria case report. Neurologia Medico-Chirurgica 199232 32-35. (https://doi. org/10.2176/nmc.32.32)

22 Amine AR \& Sugar O. Suprasellar osteogenic sarcoma following radiation for pituitary adenoma: case report. Journal of Neurosurgery 197644 88-91. (https://doi.org/10.3171/jns.1976.44.1.0088)

23 Salvati M, Cervoni L, Ciappetta P \& Raco A. Radiation-induced osteosarcomas of the skull: report of two cases and review of the literature. Clinical Neurology and Neurosurgery 199496 226-229. (https://doi.org/10.1016/0303-8467(94)90073-6)

24 Gnanalingham KK, Chakraborty A, Galloway M, Revesz T \& Powell M. Osteosarcoma and fibrosarcoma caused by postoperative radiotherapy for a pituitary adenoma: case report. Journal of Neurosurgery 200296 960-963. (https://doi.org/10.3171/ jns.2002.96.5.0960)

25 Hansen MR \& Moffat JC. Osteosarcoma of the skull base after radiation therapy in a patient with McCune-Albright syndrome: case report. Skull Base 200313 79-83. (https://doi. org/10.1055/s-2003-820562)

26 Bembo SA, Pasmantier R, Davis RP, Xiong Z \& Weiss TE. Osteogenic sarcoma of the sella after radiation treatment of a pituitary adenoma. Endocrine Practice 200410 335-338. (https://doi.org/10.4158/ EP.10.4.335)

Received in final form 2 June 2020

Accepted 15 June 2020 